\title{
What do patients think about Mercury in Dental Amalgam? Findings from Southeast part of Turkey
}

\author{
Emrullah Bahşi ${ }^{1 *}$, Bayram İnce ${ }^{1}$, Hakan Çolak², Zehra Süsgün Yıldırım ${ }^{3}$, Candan Aydın Hoş ${ }^{3}$ and Zeki \\ Akkuş ${ }^{4}$ \\ ${ }^{1}$ Department of Restorative Dentistry, Dicle University, Turkey \\ ${ }^{2}$ Department of Restorative Dentistry, Zirve University, Turkey \\ ${ }^{3}$ Department of Restorative Dentistry, Dicle University, Turkey \\ ${ }^{4}$ Department of Biostatistics, Dicle University, Turkey
}

Submission: : October 19, 2016; Published: November 29, 2016

*Corresponding author: Emrullah Bahsi, Department of Restorative Dentistry, 21280 Diyarbakır, Turkey, Tel: +90 05333088166;

Email: emrullahbahsi@hotmail.com

\begin{abstract}
Aim of the study: To research the perceptions of patients in the Diyarbakir region in respect of the toxicity of mercury in amalgam fillings.

Materials and methods: The study included 500 patients with at least one amalgam filling who attended the clinic for routine dental treatments. Data were gathered using a single-page questionnaire The questions on the form related to age, gender, marital status, level of education, economic status, types of dental filling, whether or not the amalgam filling included mercury and whether or not mercury was harmful to human health. Questions were also asked to ascertain the patient's level of knowledge in respect of mercury, amalgam fillings and human health.

Results: A total of 500 patients were included in the study, comprising 283 (56.6\%) females and 217 (43.4\%) males. When economic status was questioned, 267 (53.4\%) patients reported monthly income of 0-1000TL and $233(46.6 \%)$ patients reported more than $1000 \mathrm{TL}$. The level of education was primary school in 110 (22\%) patients, high school in 159 (31.8\%), university or post-graduate in 190 (38\%) and $41(8.2 \%)$ were illiterate. The type of dental filling was unknown by $64.4 \%$ of patients and $59.6 \%$ did not know that the amalgam filling contained mercury. $52.6 \%$ of the patients did not know whether or not mercury was harmful and $72 \%$ did not know whether or not mercury in amalgam was harmful.
\end{abstract}

Conclusion: A low level of awareness was determined in the study participants in respect of the toxicity of mercury in amalgam fillings.

Keywords: Awareness; toxicity; Mercury; Dental Amalgam

\section{Introduction}

Amalgam is a restorative material that has been widely used in dentistry applications for 160 years. Amalgam is a composite of silver, copper, tin, palladium and mercury (Hg). The ratio of mercury found in the structure of amalgam varies between $42 \%$ and $52 \%$ depending on the weight [1]. It has been reported that there may be potential toxic dangers of amalgam to patients through expression and absorption of mercury. By gradual expression from the amalgam restoration, mercury may accumulate in enamel, dentine, pulpal tissue and gingival tissue [2]. Several materials have been have been developed which can be used as an alternative to amalgam in the field of restorative dentistry, but there have been substantial criticisms of these materials because of the mercury content of amalgam and the non-aesthetic appearance. Therefore, amalgam remains a widelyused material in dental clinics [3,4]. During the application or removal of amalgam, there could be potential side-effects on the body of the expression of mercury, creating a risk for both dentists and patients of chronic fatigue, loss of strength, epilepsy, migraine, blindness and it has even been suggested that it could lead to diseases such as multiple sclerosis and Alzheimer's [5].

The main reason for debate of amalgam restorations is due to mercury. Very small amounts of elemental mercury vapour are expressed from the amalgam filling when chewing [6]. Previous scientific research has shown that after chewing, the amount of mercury in the mouth and respiration of individuals with amalgam fillings is much greater than in 
those without.7During the appication of amalgam, polishing and removal, an amount of mercury vapour is released into the environment. Although patient plasma peak mercury concentration values increase during removal, blood, plasma and urine mercury levels fall significantly after a short period and it has been repoted that if water cooling is applied during removal, this short-term increase is less. With an intra-oral increase in temperature from mechanical stimuli such as bruxism and functional activities such as chewing, teeth brushing or chewing gum, very small amounts of mercury vapour can be released into the environment.

The extent of exposure to mercury in an individual is measured in urine and blood levels. Rates of mercury in the blood and urine of those with amalgam fillings has been observed to be increased 2-5 fold [7]. A previous study examining the relationship of dentists and mercury exposure reported greater levels of poor mental concentration, emotional lability and findings of somatosensorial irritation in the group exposed to mercury compared to the group with no exposure [8]. Amalgam fillings are widely used in private clinics and public hospitals in Turkey. However, the perceptions of patients and levels of knowledge of the toxicity of mercury in amalgam fillings are unknown. The aim of this study was to investigate the pereceptions of patients in the Diyarbakir region of Turkey in respect of the toxicity of mercury in amalgam fillings.

\section{Materials and Methods}

The study was planned and conducted in the Restorative Dentistry Department of the Dental Faculty of Dicle University. The study included 500 patients with at least one amalgam filling who attended the clinic for routine dental treatments. Prior to the study, approval was granted by the Non-Invasive Clinical Research Ethics Committee of Dicle University Medical Faculty (Ethics Committee No 304, Session No:08.07.2013).

The study questionnaire was based on the based on standard, validated questions assembled from previous publications [6]. Data were gathered using a single-page questionnaire which had been developed in the standard manner. After the identification of patients with a dental amalgam filling, the study was conducted by dental assistants. Informed consent was obtained from the patients and the questionnaires were immediately completed in the clinic. Participation in the study was completely voluntary. The questions on the form related to age, gender, marital status, level of education, economic status, types of dental filling, whether or not the amalgam filling included mercury and whether or not mercury was harmful to human health. Questions were also asked to ascertain the patient's level of knowledge in respect of mercury, amalgam fillings and human health and were analysed with a Likert scale:

a. Despite the mercury content, I would have an amalgam filling

b. When there is no alternative, I would have an amalgam filling.

The responses to these statements were in the form of I completely agree-5, I agree-4, I don't know - 3, I don't agree - 2, I completely disagree -1 . The results were input to an SPSS 16.0 program and evaluated.

\section{Determination of the Level of Agreement with the Use of Amalgam}

The total weight value (TWV) of agreement was calculated as follows: $T W V=\Sigma$ n.w (n means the number of respondents for each rating and $w$ is the weight assigned to the rating). The levels of agreement (Z) were arrived at by dividing the TWV by the total number of respondents $(n=500)$.

\section{Results}

The study included 500 patients, comprising 283 (56.6\%) females and $217(43.4 \%)$ males. The age range of the patients was 15-24 years in 176 cases, 25-34 in 151 cases, 35-44 in 102 cases, $45-54$ years in 44 cases and 55 years + in 27 cases. Marital status was reported as married by 264 and single by 236 patients. Economic status was reported as $0-1000$ TL monthly income by $267(53.4 \%)$ and over $1000 \mathrm{TL}$ by $233(46.6 \%)$ patients. The level of education of the patient group was reported as primary school in 100 (22\%), high school in 159 (31.8\%), university or postgraduate in 190 (38\%) and 41 (8.2\%) patients were illiterate. Of the total patients, $64.4 \%$ did not know the type of filling and $59.6 \%$ did not know that the amalgam filling contained mercury. $52.6 \%$ of patients did not know whether or not mercury was harmful and $72 \%$ did not know whether or not the mercury in the amalgam filling was harmful (Table 1).

Table 1: The levels of knowledge in respect of the type of filling, whether or not the filling contained mercury, whether mercury is harmful to human health and whether mercury in amalgam is harmful to human health.

\begin{tabular}{|c|c|c|c|c|}
\hline Participants & $\begin{array}{l}\text { Do You Know the Type } \\
\text { of Filling That you Have? }\end{array}$ & $\begin{array}{c}\text { Do You Know That The Amalgam Filling } \\
\text { Contains Mercury? }\end{array}$ & $\begin{array}{c}\text { Do You Think } \\
\text { Mercury is } \\
\text { Harmful to Human } \\
\text { Health? }\end{array}$ & $\begin{array}{l}\text { Do You Think That } \\
\text { Mercury in Amalgam } \\
\text { Fillings is Harmful to } \\
\text { Human Health? }\end{array}$ \\
\hline $\begin{array}{c}\text { Do You Know } \\
\text { the Type of } \\
\text { Filling That you } \\
\text { Have? }\end{array}$ & $\begin{array}{c}\text { Yes: } \\
\text { 178(35.6\%) } \\
\text { No: } \\
\text { 322(64.4\%) }\end{array}$ & $\begin{array}{c}\text { Yes: } \\
\text { 202(40.4\%) } \\
\text { No: } \\
298(59.6 \%)\end{array}$ & $\begin{array}{c}\text { Yes: } \\
\text { 237(47.4\%) } \\
\text { No: } \\
\text { 84(16.8\%) } \\
\text { I don't know: } \\
\text { 179(35.8\%) }\end{array}$ & $\begin{array}{c}\text { Yes: } \\
\text { 140(28\%) } \\
\text { No: } \\
\text { 93(18.6\%) } \\
\text { I don't know: } \\
267(53.4 \%)\end{array}$ \\
\hline
\end{tabular}




\section{Advances in Dentistry \& Oral Health}

Table 2: Responses to the statement 'Despite the mercury content, I would have an amalgam filling'

\begin{tabular}{|c|c|c|c|}
\hline Level of agreement & No. of respondents (n) & Weight of ratings (w) & Contribution of each rating \\
\hline Strongly disagree & 43 & 1 & 43 \\
\hline Disagree & 138 & 2 & 276 \\
\hline Don't know & 171 & 3 & 513 \\
\hline Agree & 109 & 5 & 436 \\
\hline Strongly agree & 39 & & 195 \\
\hline Total & \multicolumn{2}{|c|}{$\mathbf{5 0 0}$} & $\mathbf{1 4 6 3}$ \\
\hline \multicolumn{2}{|c|}{ Level of agreement= } \\
\hline
\end{tabular}

Table 3: Responses to the statement, 'When there is no alternative, I would have an amalgam filling'.

\begin{tabular}{|c|c|c|c|}
\hline Level of agreement & No. of respondents (n) & Weight of ratings (w) & Contribution of each rating \\
\hline Strongly disagree & 28 & 1 & 28 \\
\hline Disagree & 73 & 2 & 346 \\
\hline Don't know & 132 & 3 & 844 \\
\hline Agree & 211 & 4 & 280 \\
\hline Strongly agree & 56 & 5 & $\mathbf{1 6 9 4}$ \\
\hline Total & \multicolumn{2}{|c|}{$\mathbf{5 0 0}$} \\
\hline
\end{tabular}

The responses to the statement, 'Despite the mercury content, I would have an amalgam filling' are presented in Table 2 and the responses to 'When there is no alternative, I would have an amalgam filling', are given in Table 3. When patients were questioned where they had learned that the amalgam filling was harmful or harmless, the responses were from the dentist or doctor in $24 \%$ of patients, from mass media in $21.4 \%$ and from their social environment in $5 \%$ of patients. When the numbers of fillings in the teeth of the patients were examined, 90 patients had 1 filling, 88 had 2 and 322 patients had 3 or more fillings. The number of amalgam fillings were determined as 1 in 174 patients, 2 in 119 patients and 3 or more in 207 patients.

\section{Discussion}

Amalgam fillings have been in widespread use for many years. However, recent studies demonstrated that due to esthetic demands and potential health concerns have led to loss of popularity of amalgam among dental patients. In Turkey, amalgam is not seen as a significant problem of debate between dental practitioners and state policies. According to the results of Zogby International Poll 76\% Americans don't know mercury is the primary component of amalgam fillings. Another study in Nigeria, it was stated that only $35 \%$ of the participant know that amalgam fillings contain mercury [6]. In our study, around $40 \%$ of participants reported that they knew amalgam fillings

contained mercury which is close to Nigerian data [6]. In a study by Faraj M et al, awareness of mercury toxicity was found to be low. That result was associated with discussions of amalgam in the North of Iraq. In addition, it was reported that the level of acceptance of amalgam fillings was related to the economic status, oral and dental education and aesthetic expectations [9].
Similarly, in the current study, the awareness of participants of the toxicity of mercury in amalgam fillings was found to be low.

The observation that the approximately half of the $(47.4 \%)$ of particiapants in the current study agree that mercury was harmful to human health is in considerably higher than with the results of a previous surveys conducted among Nigerian and North Iraq population. This level of knowledge is thought to be related to the level of education. Of the total participants, $38 \%$ had a university or postgraduate level of education. Of the participants with postgraduate education in the current study, $84.4 \%$ knew that mercury was harmful to health. In the group of participants who were illiterate, $7.3 \%$ knew that mercury was harmful to health. These findings demonstrate the importance of education and are consistent with the results of previous studies [10-12]. In respect of economic status, $75.9 \%$ of the participants in the current study with a monthly income of over 2000TL and $75.6 \%$ of those with a monthly income of over $3000 \mathrm{TL}$ knew that mercury was harmful to health.

This level of awareness shows a relationship with economic status. The level of awareness of mercury was seen to be in parallel with the level of education. Contrarily, in a study by Bamise, Oginni [6] in Nigeria demonstrated that only 26\% participants believed that mercury can cause health problem on human body even though $92 \%$ of the them were either undergraduate or graduate level. Similarly in a study by Faraj, Mohammad9 observed that $24.32 \%$ of the participants claimed to have heard about adverse reactions to dental amalgams. Bamise CT et al. [6] stated that $50 \%$ of participants in a study knew the type of fillings they had. In the same study, the importance of the use of informed consent and amalgam alternatives was reported. Various materials have 
been developed as an alternative to amalgam. However, none of these have been able to meet conditions as an economical alternative to amalgam [10]. In the current study, the vast majority of participants did not know what type of fillings they had, with only $35.6 \%$ able to state the type of dental filling. In Turkey, amalgam is used routinely in public hospitals and private clinics and is economical and easy to apply compared to other restorative materials. These features could be the reasons for preference.

In the currrent study, although the health risks of amalgam were known, it was seen to be popular among the participants. According to the results of the Likert scale analysis, while $58.52 \%$ of participants responded positively to the statement, 'Despite the mercury content, I would have an amalgam filling', $67.76 \%$ responded positively to the statement, 'When there is no alternative, I would have an amalgam filling. These results showed that patients were familiar with amalgam and that it was a popular filling material. The results of the current study were consistent with those of the study by Bamise et al. [6] In another study by Udoye and Aguwa in Nigeria, amalgam was reported to be an acceptable material by both dentists and patients [10]. Contrary to all these data, Zogby International Poll demonstrated that the majority (77 percent) of Americans would choose higher cost fillings that do not contain mercury if given the choice. Amalgam fillings and mercury have been debated in the written and visual media of most countries. When the level of awareness increases, there is seen to be an increase in these discussions. However, even if the results of this study are to be examined, discusssion of amalgam is not a priority in the Diyarbakir region.

A 2007 declaration by the World Health Organisation related to mercury recommended that exposure be reduced, that it is not used wherever possible and that support is given to alternatives. After the publication in 2008 of 'Protective Regulations' by most Health Ministers in Europe to prevent the use of mercury-based materials in children below the age of 6 years, firstly Norway, then Sweden and Denmark took the important step in the same year of formalising this as legislation. Following this process, Germany, Austria and Russia banned or restricted the use of mercury. Japan is known to have introduced this ban previously. When the involvement of the WHO and the EU is taken into consideration, the use of amalgam can be considered to have gone through the process of prohibition. It is also noticeable that in countries where it has not been banned, the majority of dentists have started to abandon this type of filling [13].

The mass media, in the form of the radio and television, are an effective way to persuade target audiences to adopt new behaviors, or to remind them of critical information. Besides informing the public about new diseases and where to seek help, they can also keep the public updated about environmental issues. The mass media can enlighten rural populations to increase their knowledge about potential toxic effect of mercury. In our study only $21 \%$ of participants report that where they had learned that the amalgam filling was harmful or harmless from mass media. This finding sugges that in Turkey mass media should take more responsibility and action to inform population on health and enviromental issues. The effects of amalgam fillings on human tissue and reported that even though there are many studies showing the effects on tissue of mercury vapour released from amalgam, there is a need for studies which would examine the relationship between neurodegenerative diseases and mercury released from amalgam, which would investigate the role of amalgam on Alzheimer's disease and multiple sclerosis and which would evaluate the neurobiological and neurodevelopmental effects of mercury in children exposed to mercury expressed from amalgam fillings of the mother during pregnancy [14].

\section{Conclusion}

The results of this study showed that the level of awareness of the toxicity of mercury was low in the study participants. Until the development of a restorative material which is as economical as amalgam, has proven long-term success and is biocompatible, then amalgam can be said to be a safe and reliable restorative material for our patients. From the results of this study in the Diyarbakir region, it can be seen that amalgam fillings were popular among the participants. When the socio-economic and educational levels of the region increase, it can be assumed that there will be an increase in perceptions and awareness.

\section{Acknowledgement}

The authors wish to thank the study participants for their contribution to the research, as well as current and past investigators and staff.

\section{References}

1. Wilson N, Lynch C (2014) Dental amalgam-time to move on. European Journal of General Dentistry 3(1): 1-2.

2. Soussa E, Shalaby Y, Maria AM, Maria OM (2013) Evaluation of oral tissue response and blood levels of mercury released from dental amalgam in rats. Arch Oral Biol 58(8): 981-988.

3. Tezel H, Ertas OS, Erakin C, Kayali A (2001) Blood mercury levels of dental students and dentists at a dental school. Br Dent J 191(8): 449452 .

4. Chin G, Chong J, Kluczewska A, Lau A, Gorjy S, et al. (2000) The environmental effects of dental amalgam. Aust Dent J 45(4): 246-249.

5. Yip HK, Li DK, Yau DC (2003) Dental amalgam and human health. Int Dent J 53(6): 464-468.

6. Bamise CT, Oginni AO, Adedigba MA, Olagundoye 00 (2012) Perception of patients with amalgam fillings about toxicity of mercury in dental amalgam. J Contemp Dent Pract 13(3): 289-293.

7. Zimmer H, Ludwig H, Bader M (2002) Determination of mercury in blood, urine and saliva for the biological monitoring of an exposure from amalgam fillings in a group with self-reported adverse health effects. Int J Hyg Environ Health 205(3): 205-211.

8. Echeverria D, Heyer NJ, Martin MD, Naleway CA, Woods JS, et al. (1995) Behavioral effects of low-level exposure to elemental $\mathrm{Hg}$ among dentists. Neurotoxicol Teratol 17(2): 161-168. 
9. Faraj BM, Mohammad HM, Mohammad KM (2015) The Changes in Dentists' Perception and Patient's Acceptance on Amalgam Restoration in Kurdistan-Iraq: A Questionnaire-based Cross-Sectional Study. J Clin Diagn Res 9(4): ZC22-ZC25.

10. Udoye C, Aguwa E (2008) Amalgam safety and dentists' attitude: a survey among a Subpopulation of Nigerian dentists. Oper Dent 33(4): 467-471.

11. Ajayi DM, O IM, Abiodun Solanke IF (2015) Perceived Health Effects of Dental Amalgam among Dentists in Selected SouthWestern State of Nigeria. Oral Hyg Health 3(2): 1-5.
12. Khairuldean N, Sadig W (1996) Amalgam safety and alternative restorative materials: a cross sectional survey among Dentists. Saudi Dent J 8(1): 27-33.

13. Mutter J (2011) Is dental amalgam safe for humans? The opinion of the scientific committee of the European Commission. J Occup Med Toxicol 6(1): 2.

14. Akgun OM, Akgun H (2012) Effects of amalgam fillings on human tissues. Turkish J Fam Pract 16(2): 83-86.

Your next submission with JuniperPublishers will reach you the below assets

- Quality Editorial service

- Swift Peer Review

- Reprints availability

- E-prints Service

- Manuscript Podcast for convenient understanding

- Global attainment for your research

- Manuscript accessibility in different formats ( Pdf, E-pub, Full Text, Audio)

- Unceasing customer service

Track the below URL for one-step submission http://juniperpublishers.com/online-submission.php 